\title{
AFETIVIDADE E HISTÓRIA EM $A$ RESISTÊNCIA, DE JULIÁN FUKS
}

\author{
Annelise Estrella Galeazzi \\ Mestranda em Letras - Teoria Literária e Literatura Comparada - pela Universidade \\ do Estado do Rio de Janeiro (UERJ) \\ anneliseestrella@yahoo.com
}

\section{LIVRO RESENHADO}

FUKS, JULIÁN. A Resistência. São Paulo: Companhia das Letras, 2015. 144p.

O romance, como gênero textual, tem sido a forma de narrar ficção mais dominante nas produções literárias do mundo contemporâneo. Popularmente, nos ensinam que esse gênero apresenta uma história em prosa mais complexa - diferente do conto, por exemplo -, com personagens psicologicamente desenvolvidos, enredo longo que, paralelamente, é atravessado por algumas tramas. Para explicar o livro A Resistência, do paulistano Julián Fuks, não poderíamos dizer na roda de amigos que se trata de um romance. O leitor logo vai perceber que não o é. Há algo nessa história que escapa às definições das teorias literárias mais tradicionais. Para além, guardando o encanto do retorno ao passado, Fuks toca em temas sensíveis como a maternidade, a adoção, o Estado e os impasses familiares.

A Resistência é narrado em primeira pessoa, sua trama, dividida em curtos capítulos, gira em torno da tentativa de se recontar a história da família do próprio narrador. O filho caçula Sebastián faz um retorno memorial desde a história da ditadura argentina de 1970, quando seus pais eram jovens estudantes militantes, guerrilheiros de esquerda, e adotaram um menino. No adentrar de pouco tempo após a adoção, com a 
força da opressão militar, a família recém-formada partiu para exílio em São Paulo, onde tiveram mais dois filhos, entre eles Sebastián.

Como dito, Sebastián decide examinar o passado e reescrever essa história a partir de seu ponto de vista, sinalizando situações que marcaram o núcleo familiar. A instabilidade e a incerteza das memórias do narrador constroem personagens que resistem o tempo todo ao próprio relato feito, assim como o próprio Sebastián conta ter resistido desde ao sono com a luz apagada quando pequeno até à lembrança da convivência com seus irmãos durante os mesmos anos da infância. O irmão adotivo é, sim, um dos temas centrais da história, em que são compartilhadas com o leitor as angustias de um adulto que hoje reconhece o impacto de ter um irmão que, muitas vezes, é reduzido justamente à característica de "adotado".

Porém, essa não é a única questão central do livro. A nacionalidade argentina dos pais proporciona um retorno e visitas à cidade de Buenos Aires, onde, andando pelas ruas e dentro de prédios conhecidos, Sebastián questiona se deve também considerar sua condição de cidadão argentino. Um país tão distante do seu íntimo e afeto como a Argentina faz com que o personagem resista a essa herança. Acontecimentos como esses fazem por vezes a leitura dolorosa, já que lembram também a carência daqueles que, na direção contrária, não se consideram mais cidadãos da terra natal e partem para o exílio, alheios a alegria e beleza da nova casa, pessoas e língua. A mudança de lar suscita fraquezas - seja por voluntariedade ou por obrigatoriedade, como foi o caso dos pais de Sebastián ao se verem despatriados perante as ordens do regime ditatorial.

A maneira pela qual a história da ditadura militar argentina é contada em $A$ Resisência está extremamente distante de ser no modelo de um "texto historiográfico". Não é possível ler o livro tal como se lê um gênero próximo da documentação histórica, 
como muito tem se produzido na literatura contemporânea, basta olharmos para o número de títulos fichados catalograficamente por "ficção histórica" nas livrarias. Nesse quesito, Fuks trabalha extremamente bem sua ars poética e com literariedade atravessa com delicadeza e sentimentalismo o tema da ditadura a partir de situações dentro do cotidiano da família. Há um episódio narrado, o jantar fracassado preparado pelos pais de Sebastián aos amigos, em que é possível sentir todo o fardo carregado pela decisão da família de estar à margem do sistema. O silêncio na sala de jantar pela ausência dos convidados é duramente sentido na leitura do trecho. Tal fracasso se deu, evidentemente, pelo medo dos amigos de ir à uma casa de militantes possivelmente vigiada pela polícia militar.

No que diz respeito à estética e à forma do livro, percebe-se que Fuks, constantemente durante seu texto, revela diferentes processos de produção escrita: ora estamos mais próximos do relato, ora mais próximos de um tom poético, ora de um diário pessoal, passando até mesmo pela possibilidade do texto vir a ser uma carta para o irmão adotivo. Além do mais, o aspecto ambíguo e intrigante de não saber muito bem se tratase de um livro de ficção ou algo mais autobiográfico - conhecida a vida do escritor - faz com que a experiência do personagem em rememorar a história da família não se manifeste mais "a partir de operações formais de distanciamento do real visíveis na estruturação narrativa, mas é o próprio argumento da trama" (GARRAMUÑO, 2012, p. 101). O próprio narrador questiona se o livro seria uma história ou não, e um dos motivos que o move para continuar é a chance de encontrar uma resposta para a pergunta.

Nesse sentido, Fuks atua como um autor "perigoso", em sentido positivo, cujo reconhecimento em seu campo de atuação começa a se dar também por colocar em questão a estrutura sobre a qual esse próprio campo geralmente sustenta as operações. 
A Resistência parece fazer parte de um conjunto de obras contemporâneas que se destacam pela ausência e dissolução de um rigor formal, e fazem do

limite entre experiência e narração um espaço de contenda. Uma contenda irritada, exasperada, ou que pode se manifestar também com certo desanimo apático, mas que aparece, com intensidades variáveis, pelo menos desde os primeiros estertores do século XIX (GARRAMUÑO, 2012, p. 93).

Já na linha temporal da narrativa, parece haver um particular esforço do autor em manter a história da família sempre como pano de fundo, mas adentrando diferentes situações, em diferentes anos, isto é, sem vínculo entre o tempo vivido e o tempo narrado. Se em um capítulo a personagem conta de uma conversa que teve, em particular, com sua mãe no quarto, no outro, conta o instante em que o irmão adotivo chegou no colo da família. Ainda, é na caracterização dos personagens que não repõe à estereótipos - construídos desde a primeira até a última página do livro - e na ausência de rigor ao gênero textual que o escritor encontra um brilhantismo destacável.

Porém, um dos elementos que parece tensionar a narrativa é a falta de ações suficientemente fortes que possam manter uma força de suspense na história. A resistência, presente não coincidentemente no título e nos pensamentos do personagem principal, encontra lugar também no ato escrito. E trava, trava a história. Se para o narrador é difícil fazer o retorno ao seu próprio passado perdido e irrecuperável, o que faz com que ele resista a sua própria biografia, ao leitor pode parecer que não há vontade e pulsão nessa prosa.

Alguns trechos, como "Sou e não sou o homem que atravessa o corredor, sinto e não sinto o peso das pernas que se movem, ouço e não ouço o choque dos pés contra o 
chão" (FUKS, 2017, p. 138), recorrentes durante o texto todo - e arrisco dizer que Fuks peca pelo excesso deles - trouxeram descontentamento a minha experiência de leitura. Percebe-se muita força e insistência na ânsia de dar um passo atrás, de não escrever o livro, de não investigar o passado, de resistir a absolutamente tudo que o narrador tem, que, acredito eu, pode frustrar o leitor.

Há, de certo, a criação de um pacto de ambiguidade pelo narrador com o leitor para que este entenda o jogo de "vai" e "não vai" atravessar o corredor, "vai" e "não vai" contar a história do irmão adotado, "vai" e "não vai" continuar escrevendo o livro, "vai" e "não vai" entender os conflitos da vida familiar, "sabe" e "não sabe" o passado do pai, entre tantas outras dualidades. Esse sujeito fragmentado que é Sebástian, perdido entre o passado e a imobilidade do presente, não vê

como dizer sua experiência senão de forma vaga, insegura, recortada. Os capítulos breves, as cenas sobrepostas, as idas e vindas, as reticências e as inseguranças das armações, tudo aponta para a fragilidade da representação, mas sem jamais renunciar a ela. A ideia do fracasso, nesse sentido, marca a dicção de suas vozes, longe novamente da condição irônica pós-moderna, e sim como reconhecimento da negatividade dessa forma de experiência e como condição de sua expressão (TURIN, 2017, p. 61).

No entanto, o que mantém esse pacto de ambiguidade com o leitor? Vejo que, justamente, a falta de ações que mantenham sua força e a incerteza do narrador em não saber o por quê da recuperação de sua trajetória trazem problemas para a leitura. Reconheço que essa dificuldade do narrador em recuperar seu passado é trazida ao texto a partir de um procedimento formal que soma argumento do romance, mas, como dito, o repetido fracasso pode não produz bons efeitos na leitura. 
Por fim, vejo que a história contada em $A$ Resistência é como uma cicatriz velha, ainda aberta - e que talvez nunca venha a ser fechada. Mas, agora, ao menos, essa cicatriz pode ser compartilhada fora do próprio núcleo familiar que, dado o contexto político-social vivido, a criou. A coexistência dos acontecimentos familiares com aquilo que envolve as consequências da ditadura militar argentina significa bravamente uma interiorização afetiva da violência histórica que os pais sofreram e, de alguma maneira, repassaram a seus filhos. Fuks trabalha com os restos do real e da História. Tenta reconstruí-los a partir de sua memória, palavras e afetividade, trazendo a nós um livro que permite a reflexão de que a própria vida talvez seja mesmo também "construída com os escombros e as ruínas que a experiência e os acontecimentos depositam sobre a superfície opaca da existência" (GARRAMUÑO, 2012, p. 98).

\section{Referências}

GARRAMUÑO, F. A experiência opaca: literatura e desencanto. Rio de Janeiro: Eduerj, 2012.

TURIN, R. A polifonia do tempo: ficção, trauma e aceleração no Brasil contemporâneo. ArtCultura, Uberlândia, MG, v. 19, n. 35, p. 55-70, jul.-dez. 2017.

Recebido em 24 de fevereiro de 2018.

Aceito em 8 de março de 2018. 